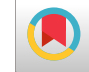

\title{
Association Between Interleukin-33 Polymorphism and Henoch-Schönlein Purpura in Chinese Children
}

\author{
Youhong Fang ${ }^{1}$, Wei $\mathrm{Li}^{2}$, Hui Xu ${ }^{2}$, Jianhua $\mathrm{Mao}^{3}$ and Shiqiang Shang ${ }^{2, *}$ \\ ${ }^{1}$ Department of Gastroenterology, Children's Hospital, Zhejiang University School of Medicine, Hangzhou, China \\ ${ }^{2}$ Department of Clinical Laboratory, Children's Hospital, Zhejiang University School of Medicine, Hangzhou, China \\ ${ }^{3}$ Department of Nephrology, Children's Hospital, Zhejiang University School of Medicine, Hangzhou, China \\ "Corresponding author: Children's Hospital, Zhejiang University School of Medicine, 3333 Bin Sheng Road, Hangzhou, China. Tel: +86-057187061007, Fax: +86-057187033296, \\ Email: shangsq@zju.edu.cn
}

Received 2017 October 19; Revised 2017 December 10; Accepted 2018 January 01.

\begin{abstract}
Objectives: Interleukin-33 (IL-33) was one of the members of IL-1 family, and it was reported that the single nucleotide polymorphisms (SNPs) in the IL-33 gene was contribute to the susceptibility to immune related diseases, including rheumatoid arthritis, asthma, Behcet's disease, systemic lupus erythematosus and ankylosing spondylitis. However, the potential association between SNPs in IL-33 gene and Henoch-Schönlein purpura (HSP) was not explored.

Methods: We designed a case-control study, a total of $181 \mathrm{HSP}$ patients and 202 healthy pediatric controls were included, which aimed to study the relationship between the SNPs in the IL-33 gene (rs1929992, rs7044343) and HSP with a Chinese pediatric cohort. Results: There were no evidence for the association of rs1929992 and rs7044343 polymorphism in IL-33 gene with pediatric HSP patients (C versus T, $P=0.622, \mathrm{OR}=0.931,95 \% \mathrm{CI}: 0.7-1.238$; TT versus CC, $P=0.742$, $\mathrm{OR}=0.908,95 \% \mathrm{CI}: 0.513-1.609$; $\mathrm{CT}$ versus CC, $P=$ $0.158, \mathrm{OR}=0.714,95 \% \mathrm{CI}: 0.446-1.141$ and $\mathrm{C}$ versus T, $P=0.920, \mathrm{OR}=0.986,95 \% \mathrm{CI}: 0.742-1.309$; TT versus $\mathrm{CC}, P=0.939, \mathrm{OR}=0.978,95 \% \mathrm{CI}$ : $0.549-1.741$; CT versus CC, $P=0.416, \mathrm{OR}=0.817,95 \% \mathrm{CI}$ : 0.501-1.331, respectively). Moreover, association studies were performed on the correlation between IL-33 gene polymorphisms and HSP nephritis patients as well as patients with gastrointestinal manifestation and joint involvement. However, there were no significant association regarding the distribution of allele and genotype frequencies between HSP patients with different system involvement and healthy controls either.

Conclusions: The present findings indicated that both of rs1929992 and rs7044343 in gene IL-33 polymorphism were not related to the susceptibility to HSP and the different system involvement of HSP patients.
\end{abstract}

Keywords: Henoch-Schönlein Purpura, Cytokines, Interleukin-33, Single Nucleotide Polymorphisms

\section{Background}

Henoch-Schönlein purpura (HSP) was recognized as leukocytoclastic vasculitis which involving small vessels. HSP was also the most common vasculitis during childhood (1). It usually occurs in children between three and 15 years of age. The most common clinical presentations of HSP include cutaneous palpable purpura, arthritis or arthralgias, hematuria and/or proteinuria, bowel angina and gastrointestinal (GI) bleeding (2). However, the etiology of HSP is not fully understand. Genetic predisposition may contribute to this immune mediated inflammatory disease. It is demonstrated that multiple genes and their interactions with environmental factors were involved in the susceptibility to HSP (3). MEFV and human leukocyte antigen haplotypes also played a role in susceptibility to $\operatorname{HSP}(4,5)$. Gene-gene interaction effects of CCL2, VEGF and $A C E$ genes also reported to relate with HSP (6). Moreover, multiple studies have showed the role of polymorphisms of a variety of genes was associated with the risk of HSP, HSP nephritis (HSPN) and HSP associated joint diseases (7-9).

Interleukin-33 (IL-33) was a proinflammatory cytokine which was belonged to the IL-1 cytokine family (10), and the intracellular signaling pathway of IL-33 was similar with IL-1 (11). IL-33 activated nuclear factor (NF)-kappa B and mitogen-activated protein kinases (MAPKs) via IL-1 receptor ST2 (11). Furthermore, IL-33 was expressed in various cells which were response to tissue damage, and acted as an early alertor of inflammation (12). The production of IL33 was increased in inflamed tissues, which lead to the further amplification of inflammatory responses (13).

Previous study showed IL-33/ST2 signal transduction pathway was associated with a brunch of autoimmune and allergic diseases, as well as a variety of renal diseases (14). The levels of serum IL-33 in rheumatoid arthritis (RA) patients were observed significantly higher than these in 
healthy controls. And CC genotype of rs7044343 in the gene of IL-33 was associated with RA patients and down regulated IL-33 expression in RA patients (15). IL-33 also played a crucial role in Th2-mediated airway diseases like asthma (16). However, the relationship between IL-33 and HSP was poorly understand. Chen et al. (17) showed the level of serum IL-33 were elevated in acute stage of HSP patients and they were related to the severity of the disease. These findings suggested that IL-33 might contribute to the pathogenesis of HSP. The polymorphism of SNPs (rs1929992 and rs7044343) in IL-33 gene were the most commonly reported SNPs associated with immune related diseases.

\section{Objectives}

The purpose of this study was to explore the relationship of SNPs (rs1929992 and rs7044343) polymorphism in IL-33 gene with HSP.

\section{Methods}

\subsection{Patients and Methods}

181 patients who diagnosed as HSP and 202 healthy pediatric controls between June 2011 and June 2013 in Children's hospital, Zhejiang University School of medical were included in this study. HSP patients were diagnosed according to the American College of Rheumatology criteria for the classification of HSP (18). All patients were diagnosed as HSP first time and followed up more than 6 months. Patients accompanied with other systemic vasculitis and other immune related diseases were excluded. A total of 202 healthy children without a history of HSP and immune related diseases were randomly chosen as control in the study. HSP patients were divided into three groups based on main clinical manifestations, patients with HSPN which was defined as the presence of proteinuria and/or hematuria, joint manifestations refer to arthralgia or peripheral arthritis, patients with GI involvement including bowel angina and gastrointestinal bleeding.

The general information and clinical features of HSP patients and controls were obtained from the medical recording system. Laboratory findings such as white blood count, serum levels of albumin, creatinine, and complement 3 (C3), immunoglobulin (Ig) A and urine protein of HSP patients during the acute stage were extracted. Glomerular filtration rate (GFR) was calculated by Schwartz formula.

The study was approved by the Ethics Committee of Children's Hospital, Zhejiang University School of Medicine, and written informed consent was obtained from all the parents of children.

\subsection{Analysis of IL-33 Gene Polymorphism}

EDTA anti-coagulated peripheral venous blood was obtained from each HSP patient and control. DNA of the leukocytes was extracted with a DNA extraction kit (Tissuebank Biotechnology Co, Ltd., Shanghai, China) following the instruction protocol. DNA samples were stored at $-20^{\circ} \mathrm{C}$ for polymerase chain reaction analysis.

SNP genotyping was performed in a 384-well plate format on the Sequenom MassARRAY platform (Sequenom, San Diego, USA), as described previously (19). The primers for IL-33 rs1929992 were 5'-ACGTTGGATGGGTCATTAGTTTTGGTGAAA-3' (forward) and 5'-ACGTTGGATGTAGCTCTTTTCTTTCATGG-3' (reverse). The primers for IL-33 rs7044343 were $5^{\prime}$ ACGTTGGATGAAGAGGAATGAATATTGGG-3' (forward) and 5'-ACGTTGGATGTTGTGACCCTAATGGTTA-3' (reverse). IL-33 rs1929992 and rs7044343 were amplified with total volume $5 \mu \mathrm{L}$ in each tube. Each tube was consisted of $5 \mathrm{ng}$ of DNA, 1 $\mu \mathrm{M}$ forward and reverse primers, $0.5 \mathrm{mM}$ dNTP, PCR buffer and 0.1 $\mu$ L HotStar Taq (Qiagen). The PCR thermal-cycling condition was as follow: 15 minutes at $94^{\circ} \mathrm{C}$ and 45 cycles of 20 seconds at $94^{\circ} \mathrm{C}, 30$ seconds at $56^{\circ} \mathrm{C}$ and 1 minute at $72^{\circ} \mathrm{C}$. After dNTPs were removed, Single base extension for SNP was performed in reaction buffer: $1 \mathrm{X}$ iPLEX buffer, 0.2 $\mu \mathrm{L}$ stop mixture, $0.041 \mu \mathrm{L}$ iPLEX enzyme (Sequenom, San Diego, USA), $0.804 \mu \mathrm{L} 10 \mu \mathrm{M}$ extension primer and $\mathrm{H} 2 \mathrm{O}$. The PCR thermal-cycling condition for extension was as follow: 30 seconds at $94^{\circ} \mathrm{C}$ and 40 cycles of 5 seconds at $94^{\circ} \mathrm{C}, 5$ seconds at $52^{\circ} \mathrm{C}$ and 5 seconds at $80^{\circ} \mathrm{C}$. Genotype calling was performed in real time with MassARRAY RT software (version 3.0.0.4) (Sequenom, San Diego, USA). SNP genotyping was performed via MassARRAY Typer software (version 3.4) (Sequenom, San Diego, USA).

\subsection{Statistical Analysis}

The age of disease onset and laboratory results were described as mean $\pm \mathrm{SD}$, the mean values compared between patients and controls used the unpaired student's $t$ test. Hardy-Weinberg equilibrium (HWE) for each SNP in patients and controls were tested by chi-square goodnessof-fit test. The frequencies of gender, allele and genotype between the two groups were compared using chi-square $\left(\chi^{2}\right)$ test. The odds ratios (OR) and the significant of OR were calculated to evaluate the risk of developing HSP. P $<0.05$ was considered statistically significant difference. All statistical analyses were conducted with SPSS 22.0 statistical software (SPSS Inc., IBM Corp. Armonk, NY, United States).

\section{Results}

4.1. The General Information, Clinical Features of HSP Patients

The general information and clinical features of the 181 HSP patients and 202 healthy controls were listed in Table 
1. Mean age of disease onset was $7.8 \pm 2.6$ years, mean age of healthy control was $7.0 \pm 2.1$ years. There were no statistical differences between the HSP patients and controls regarding to age of disease onset and gender, $\mathrm{P}>0.05$.

\subsection{HWE and Statistical Power Examination}

The P-value for HWE examination of the prevalence of genotypes regarding two SNPs in healthy controls and HSP group were both higher than 0.05, there were no statistically differences (Table 2 ).

\subsection{Association of IL-33 Gene Polymorphisms and Risk of HSP}

There were no significant differences between HSP patients and healthy controls for the association of rs1929992 and rs7044343 polymorphism with risk of HSP. With respect to rs1929992, $\mathrm{C}$ versus T, $P=0.622, \mathrm{OR}=0.931,95 \% \mathrm{CI}$ : $0.700-1.238$; TT versus CC, $\mathrm{P}=0.742, \mathrm{OR}=0.908,95 \% \mathrm{CI}: 0.513$ -1.609; CT versus CC, $P=0.158, \mathrm{OR}=0.714,95 \% \mathrm{CI}$ : $0.446-1.141$ (Table 3). With respect to rs7044343, $\mathrm{C}$ versus T, $P=0.920$, $\mathrm{OR}=0.986,95 \% \mathrm{CI}: 0.742-1.309$; TT versus CC, $P=0.939$, OR $=0.978,95 \%$ CI: $0.549-1.741$; $\mathrm{CT}$ versus $\mathrm{CC}, P=0.416$, OR $=$ 0.817, 95\% CI: $0.501-1.331$ (Table 4).

\begin{tabular}{|c|c|c|}
\hline Parameters & Patients & Controls \\
\hline $\mathbf{N}$ & 181 & 202 \\
\hline Age at disease onset & $7.8 \pm 2.6$ & $7.0 \pm 2.1$ \\
\hline \multicolumn{3}{|l|}{ Gender } \\
\hline Male & 99 & 108 \\
\hline Female & 82 & 94 \\
\hline Arthralgias and/or arthritis & 103 & - \\
\hline Gastrointestinal involvement & 108 & - \\
\hline Renal involvement & 81 & - \\
\hline WBC $\left(\times 10^{9} / L\right)$ & $10.08 \pm 4.46$ & - \\
\hline CRP & $7.97 \pm 13.94$ & - \\
\hline ESR & $16.66 \pm 16.51$ & - \\
\hline Serum creatinine, $\mathbf{m g} / \mathbf{d L}$ & $0.51 \pm 1.87$ & - \\
\hline $\mathrm{C}_{3}, \mathrm{~g} / \mathrm{L}$ & $1.23 \pm 0.25$ & - \\
\hline IgA, $\mathbf{g} / \mathbf{L}$ & $2.00 \pm 0.80$ & - \\
\hline ALB, $\mathbf{g} / \mathbf{L}$ & $40.36 \pm 5.84$ & - \\
\hline GFR, $\mathrm{mL} / \mathrm{min} / 1.73 \mathrm{~m}^{2}$ & $146.51 \pm 44.33$ & - \\
\hline
\end{tabular}

Abbreviations: ALB, albumin; C3, complement 3; CRP, C-reactive protein; GFR, glomerular filtration rate; HSP, Henoch-Schönlein purpura; IgA, immunoglobulin A; SD, standard deviation; WBC, white blood count.

${ }^{a}$ Values are expressed as No. or mean $\pm S D$.
4.4. Correlation Between IL-33 Gene Polymorphisms and Risk of HSPN, GI Involvement and Joint Involvement

In this study, 81 HSP patients (40.3\%) accompanied with HSPN, 108 patients (53.73\%) had GI manifestations, including abdominal pain and GI bleeding, and 103 patients (51.24\%) had arthralgias. We also compared the allele and genotype frequencies of HSP patients with HSPN, accompanied GI manifestations and joint involvement with healthy controls, respectively. Results showed that there was no significant difference with allele and genotype frequencies for the two SNPs (rs1929992, rs7044343) in IL-33 gene between HSP patients with different manifestations and healthy controls (Table 3 ).

\section{Discussion}

HSP was known as an immune mediated vasculitis that might be associated with predisposition and infection of some pathogens. It most commonly happened in autumn or winter preceding upper respiratory tract infections with multiple pathogens, such as Streptococcus strains, parainfluenza virus and parvovirus B19 (20, 21). However, the pathophysiology of HSP was not completely understood so far. The deposition of immune complexes containing IgA1 in the vascular played a vital role in the pathogenic of disease (22). The disorder of immune reaction might result in inflammation and vasculitis without a granulomatous reaction (23). Many antibodies, cytokines, chemokines, receptors, and transmembrane proteins have been supposed to involved in the development of the disease (6). Several cytokines, such as tumor necrosis factor alpha (TNF-alpha), IL-6, IL-8 and IL-17 were also related to the risk and development of HSP (24).

IL-33 had been found to participate in asthma, inflammation, and variety of immune disorders (25). IL-33 induced pro-inflammatory effects via activates $\mathrm{T}$ helper type 2 (Th2) cells and mast cells, additionally, it also played a role depending on Th1/Th17 immune response $(11,26)$. IL-33 was considered as an 'endogenous danger signal' for its alerting effect in the immune system when tissue was damaged and infected, and it could lead to the initiation of a healing of damage further (27).

The variety of SNPs in IL-33 were studied in many immune related diseases and revealed that some allele genes and genotype of IL-33 gene were associated with risk to immune related diseases. GWAS studies revealed that rs1342326 (28), rs3939286 (29), and rs2381416 (30) SNPs in IL-33 gene were related to the risk of asthma (19). The CC genotype of rs7044343 in IL-33 was associated with susceptibility to RA, while, no association was detected between rs10975514 polymorphism and RA susceptibility (15). Another study showed that SNPs rs1891385, rs2210463, 


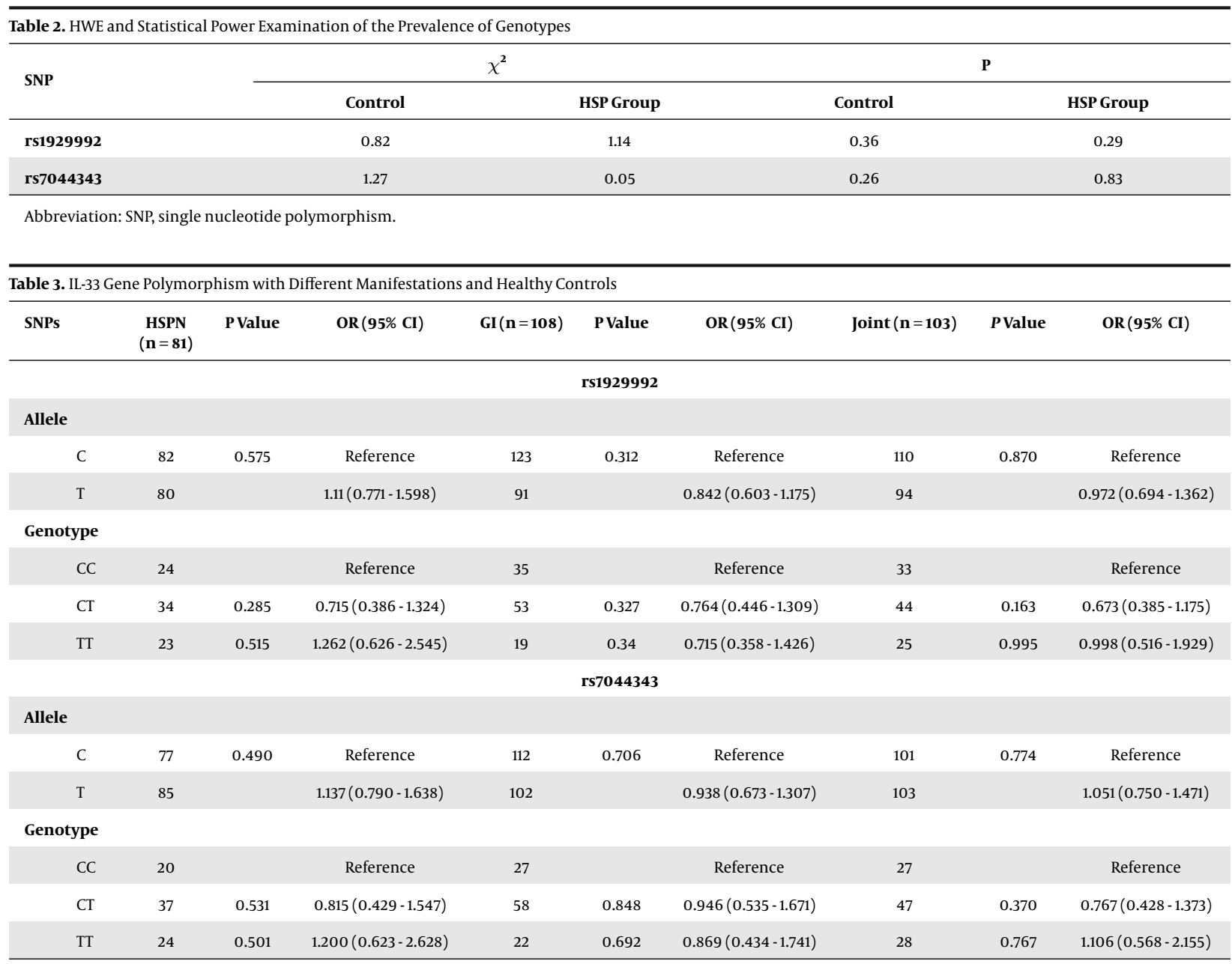

rs10118795, rs1929992, rs10975519, and rs1048274 in the IL33 gene were associated to the development of ankylosing spondylitis (AS) in a Chinese Han population (31). The rs7044343 and rs11792633 polymorphism of IL-33 gene decreased risk of Behcet's disease (BD), which means it acted a protective role during the pathogenesis of BD (32). Xu et al. (33) found that there was significantly lower expression of allele G for rs1929992 in systemic lupus erythematosus (SLE) patients than that in controls, and genotype GG was associated to the susceptibility to SLE when compared with the AA. Meanwhile there is no evidence for the association of rs7044343 polymorphism in IL-33 gene with SLE.

In this study, we investigated the correlation between the SNPs of IL-33 gene polymorphism (rs1929992, rs7044343) and HSP in a Chinese Han pediatric cohort that consisted of 181 HSP patients and 202 healthy controls. We showed that there was no strong evidence for the association of IL-33 gene (rs1929992, rs7044343) polymorphism with the risk of HSP. Furthermore, association studies performed on the relationship with these two polymorphisms between healthy controls and HSP patients with different system involved (HSPN, joint involvement and GI involvement) showed no significant association as well. Although HSP was reported related to the immune disorder disease. Moreover, serum IL-33 level and SNPs in IL-33 gene were related to the risk of disease, severity of autoimmune diseases and renal injury. Nevertheless, we didn't observe any relationship between IL-33 gene polymorphism (rs1929992, rs7044343) and HSP in our study. It remained further investigation with larger population and different ethnicity.

In conclusion, to our knowledge, this was the first study to discuss the association between IL-33 gene polymorphisms and the risk of HSP. The present research suggested that the IL-33 gene (rs1929992 and rs7044343) were not related to HSP susceptibility in Chinese pediatric population. 


\begin{tabular}{|c|c|c|c|c|c|c|c|c|}
\hline \multirow{2}{*}{ SNPs } & \multicolumn{2}{|c|}{ Controls $(n=202)$} & \multicolumn{2}{|c|}{$\operatorname{HSP}(n=181)$} & \multicolumn{2}{|c|}{ PValue } & \multicolumn{2}{|c|}{ OR $(95 \% \mathrm{CI})$} \\
\hline & rs1929992 & rs7044343 & rs1929992 & rs7044343 & rs1929 & 2 rs7044343 & rs1929992 & rs7044343 \\
\hline \multicolumn{9}{|l|}{ Allele } \\
\hline $\mathrm{C}$ & $215(53.22 \%)$ & $205(50.74 \%)$ & $198(55.00 \%)$ & $185(51.10 \%)$ & 0.622 & 0.920 & Reference & Reference \\
\hline \multicolumn{9}{|l|}{ Genotype } \\
\hline $\mathrm{CC}$ & 54 & 48 & 58 & 48 & & & Reference & Reference \\
\hline $\mathrm{CT}$ & 107 & 109 & 82 & 89 & 0.158 & 0.416 & $0.714(0.446-1.141)$ & $0.817(0.501-1.331)$ \\
\hline TT & 41 & 45 & 40 & 44 & 0.742 & 0.939 & $0.908(0.513-1.609)$ & $0.978(0.549-1.741)$ \\
\hline \multicolumn{9}{|l|}{ Dominant } \\
\hline $\mathrm{CC}$ & 54 & 48 & 58 & 48 & 0.239 & 0.534 & Reference & Reference \\
\hline $\mathrm{CT}+\mathrm{TT}$ & 148 & 154 & 122 & 133 & & & $0.767(0.494-1.193)$ & $0.864(0.544-1.371)$ \\
\hline \multicolumn{9}{|l|}{ Recessive } \\
\hline $\mathrm{CC}+\mathrm{CT}$ & 161 & 157 & 140 & 137 & 0.646 & 0.638 & Reference & Reference \\
\hline TT & 41 & 45 & 40 & 44 & & & $1.122(0.687-1.833)$ & $1.121(0.697-1.801)$ \\
\hline
\end{tabular}

\section{Footnotes}

Conflict of Interests: The authors declare no conflicts of interests.

Ethical Considerations: The study was approved by the Ethics Committee of Children's Hospital, Zhejiang University School of Medicine, and written informed consent was obtained from all the parents of children.

Funding/Support: There is no financial support.

\section{References}

1. Yang YH, Tsai IJ, Chang CJ, Chuang YH, Hsu HY, Chiang BL. The interaction between circulating complement proteins and cutaneous microvascular endothelial cells in the development of childhood Henoch-Schonlein purpura. PLoS One. 2015;10(3). e0120411. doi: 10.1371/journal.pone.0120411. [PubMed: 25760949]. [PubMed Central: PMC4356510].

2. Calvo-Rio V, Loricera J, Mata C, Martin L, Ortiz-Sanjuan F, Alvarez L, et al. Henoch-Schonlein purpura in northern Spain: Clinical spectrum of the disease in 417 patients from a single center. Medicine (Baltimore). 2014;93(2):106-13. doi: 10.1097/MD.0000000000000019. [PubMed: 24646467]. [PubMed Central: PMC4616305].

3. Rigante D, Castellazzi L, Bosco A, Esposito S. Is there a crossroad between infections, genetics, and Henoch-Schonlein purpura? Autoimmun Rev. 2013;12(10):1016-21. doi: 10.1016/j.autrev.2013.04.003. [PubMed: 23684700].

4. Gershoni-Baruch R, Broza Y, Brik R. Prevalence and significance of mutations in the familial Mediterranean fever gene in HenochSchonlein purpura. J Pediatr. 2003;143(5):658-61. doi: 10.1067/S00223476(03)00502-X. [PubMed: 14615741].

5. Peru H, Soylemezoglu O, Gonen S, Cetinyurek A, Bakkaloglu SA, Buyan $\mathrm{N}$, et al. HLA class 1 associations in Henoch Schonlein purpura: Increased and decreased frequencies. Clin Rheumatol. 2008;27(1):5-10. doi: 10.1007/s10067-007-0640-z. [PubMed: 17487448].

6. Mohammadian T, Bonyadi M, Nabat E, Rafeey M. Association of ACE, VEGF and CCL2 gene polymorphisms with Henoch-Schonlein purpura and an evaluation of the possible interaction effects of these loci in HSP patients. Adv Clin Exp Med. 2017;26(4):661-4. doi: 10.17219/acem/62896. [PubMed: 28691415].

7. He X, Lu H, Kang S, Luan J, Liu Z, Yin W, et al. MEFV E148Q polymorphism is associated with Henoch-Schonlein purpura in Chinese children. Pediatr Nephrol. 2010;25(10):2077-82. doi: 10.1007/s00467-0101582-2. [PubMed: 20602240].

8. Li J, Liu H. P-selectin gene -825 polymorphism is associated with risk of Henoch-Schonlein purpura nephritis. Clin Exp Rheumatol. 2011;29(1 Suppl 64). S134. [PubMed: 21385561].

9. An J, Lu Q, Zhao H, Cao Y, Yan B, Ma Z. A study on the association between C1GALT1 polymorphisms and the risk of Henoch-Schonlein purpura in a Chinese population. Rheumatol Int. 2013;33(10):2539-42. doi: 10.1007/s00296-013-2761-9. [PubMed: 23624553].

10. Baekkevold ES, Roussigne M, Yamanaka T, Johansen FE, Jahnsen FL, Amalric F, et al. Molecular characterization of NF-HEV, a nuclear factor preferentially expressed in human high endothelial venules. Am J Pathol. 2003;163(1):69-79. doi: 10.1016/S0002-9440(10)63631-0. [PubMed: 12819012]. [PubMed Central: PMC1868188].

11. Schmitz J, Owyang A, Oldham E, Song Y, Murphy E, McClanahan TK, et al. IL-33, an interleukin-1-like cytokine that signals via the IL-1 receptorrelated protein ST2 and induces T helper type 2-associated cytokines. Immunity. 2005;23(5):479-90. doi: 10.1016/j.immuni.2005.09.015. [PubMed: 16286016].

12. Miller AM. Role of IL-33 in inflammation and disease.J Inflamm (Lond). 2011;8(1):22. doi: 10.1186/1476-9255-8-22. [PubMed: 21871091]. [PubMed Central: PMC3175149].

13. Palmer $\mathrm{G}$, Gabay C. Interleukin-33 biology with potential insights into human diseases. Nat Rev Rheumatol. 2011;7(6):321-9. doi: 10.1038/nrrheum.2011.53. [PubMed: 21519352].

14. Chen WY, Li LC, Yang JL. Emerging roles of IL-33/ST2 axis in renal diseases. Int J Mol Sci. 2017;18(4). doi: 10.3390/ijms18040783. [PubMed: 28387719]. [PubMed Central: PMC5412367].

15. Li C, Mu R, Guo J, Wu X, Tu X, Liu X, et al. Genetic variant in IL33 is associated with susceptibility to rheumatoid arthritis. Arthritis Res Ther. 2014;16(2):R105. doi: 10.1186/ar4554. [PubMed: 24779919]. [PubMed Central: PMC4075243].

16. Prefontaine D, Lajoie-Kadoch S, Foley S, Audusseau S, Olivenstein R, Halayko AJ, et al. Increased expression of IL-33 in severe asthma: evidence of expression by airway smooth muscle cells. J Immunol. 
2009;183(8):5094-103. doi: 10.4049/jimmunol.0802387. [PubMed: 19801525].

17. Chen T, Jia RZ, Guo ZP, Cao N, Li MM, Jiao XY. Elevated serum interleukin-33 levels in patients with Henoch-Schonlein purpura. Arch Dermatol Res. 2013;305(2):173-7. doi: 10.1007/s00403-012-1268-7. [PubMed: 22836779].

18. Mills JA, Michel BA, Bloch DA, Calabrese LH, Hunder GG, Arend WP, et al. The American College of Rheumatology 1990 criteria for the classification of Henoch-Schonlein purpura. Arthritis Rheum. 1990;33(8):1114-21. doi: 10.1002/art.1780330809. [PubMed: 2202310].

19. Duan L, Huang Y, Su Q, Lin Q, Liu W, Luo J, et al. Potential of IL-33 for preventing the kidney injury via regulating the lipid metabolism in gout patients. J Diabetes Res. 2016;2016:1028401. doi: 10.1155/2016/1028401. [PubMed: 27579324]. [PubMed Central: PMC4992512].

20. Weiss PF, Klink AJ, Luan X, Feudtner C. Temporal association of Streptococcus, Staphylococcus, and parainfluenza pediatric hospitalizations and hospitalized cases of Henoch-Schonlein purpura. J Rheumatol. 2010;37(12):2587-94. doi: 10.3899/jrheum.100364. [PubMed: 20843903].

21. Miron D, Luder A, Horovitz Y, Izkovitz A, Shizgreen I, Ben David E, et al. Acute human parvovirus B-19 infection in hospitalized children: A serologic and molecular survey. Pediatr Infect Dis J. 2006;25(10):898901. doi: 10.1097/01.inf.0000237865.01251.d2. [PubMed: 17006284].

22. Inoue $\mathrm{CN}$, Matsutani S, Ishidoya $\mathrm{M}$, Homma R, Chiba Y, Nagasaka T. Periodontal and ENT therapy in the treatment of pediatric Henoch-Schonlein purpura and IgA nephropathy. Adv Otorhinolaryngol. 2011;72:53-6. doi: 10.1159/000324605. [PubMed: 21865689].

23. Palit A, Inamadar AC. Childhood cutaneous vasculitis: A comprehensive appraisal. Indian J Dermatol. 2009;54(2):110-7. doi: 10.4103/00195154.53179. [PubMed: 20101304]. [PubMed Central: PMC2807148].

24. Jen HY, Chuang YH, Lin SC, Chiang BL, Yang YH. Increased serum interleukin-17 and peripheral Th17 cells in children with acute Henoch-Schonlein purpura. Pediatr Allergy Immunol. 2011;22(8):862-8. doi: 10.1111/j.1399-3038.2011.01198.x. [PubMed: 21929599].

25. Liew FY, Pitman NI, McInnes IB. Disease-associated functions of IL-33: the new kid in the IL-1 family. Nat Rev Immunol. 2010;10(2):103-10. doi: 10.1038/nri2692. [PubMed: 20081870].

26. Vocca L, Di Sano C, Uasuf CG, Sala A, Riccobono L, Gangemi S, et al. IL-33/ST2 axis controls Th2/IL-31 and Th17 immune response in allergic airway diseases. Immunobiology. 2015;220(8):954-63. doi: 10.1016/j.imbio.2015.02.005. [PubMed: 25747940].

27. Nile CJ, Barksby E, Jitprasertwong P, Preshaw PM, Taylor JJ. Expression and regulation of interleukin-33 in human monocytes. Immunology. 2010;130(2):172-80. doi: 10.1111/j.1365-2567.2009.03221.x. [PubMed: 20070408]. [PubMed Central: PMC2878462].

28. Moffatt MF, Gut IG, Demenais F, Strachan DP, Bouzigon E, Heath $S$, et al. A large-scale, consortium-based genomewide association study of asthma. N Engl J Med. 2010;363(13):1211-21. doi: 10.1056/NEJMoa0906312. [PubMed: 20860503]. [PubMed Central: PMC4260321].

29. Gudbjartsson DF, Bjornsdottir US, Halapi E, Helgadottir A, Sulem P, Jonsdottir GM, et al. Sequence variants affecting eosinophil numbers associate with asthma and myocardial infarction. Nat Genet. 2009;41(3):342-7. doi: 10.1038/ng.323. [PubMed: 19198610].

30. Torgerson DG, Ampleford EJ, Chiu GY, Gauderman WJ, Gignoux CR, Graves PE, et al. Meta-analysis of genome-wide association studies of asthma in ethnically diverse North American populations. Nat Genet. 2011;43(9):887-92. doi: 10.1038/ng.888. [PubMed: 21804549]. [PubMed Central: PMC3445408].

31. Fan D, Ding N, Yang $T$, Wu S, Liu S, Liu L, et al. Single nucleotide polymorphisms of the interleukin-33 (IL-33) gene are associated with ankylosing spondylitis in Chinese individuals: A case-control pilot study. Scand J Rheumatol. 2014;43(5):374-9. doi: 10.3109/03009742.2014.882408. [PubMed: 24825247].

32. Koca SS, Kara M, Deniz F, Ozgen M, Demir CF, Ilhan N, et al. Serum IL-33 level and IL-33 gene polymorphisms in Behcet's disease. Rheumatol Int. 2015;35(3):471-7. doi: 10.1007/s00296-014-3111-2. [PubMed: 25119832].

33. Xu W, Liu Y, Ye D. Association between IL-33 gene polymorphisms (rs1929992, rs7044343) and systemic lupus erythematosus in a Chinese Han Population. Immunol Invest. 2016;45(7):575-83. doi: 10.1080/08820139.2016.1193868. [PubMed: 27603301]. 